\title{
Juan Moreira en un Contexto Modernista
}

El estudio del movimiento modernista en el Rio de la Plata ha estado por lo general confinado al examen de la poesía lírica. ${ }^{1}$ Los crïticos se han detenido más en los aspectos estéticos del movimiento, y sobretodo en la influencia del parnaso y del simbolismo francés, o aún del decadentismo.

Manuel Pedro González, en su vehemente ensayo "En torno a la iniciación del modernismo", confirma esta parcialidad de enfoque y nota cómo la prosa fue siempre considerada "un producto de menor rango artístico." $\mathrm{El}$ crítico subraya como "No han parado mientes los escoliastas del movimiento en el hecho de que dicha renovación se realizó en la prosa mucho antes que en el verso", y sigue: "Testimonio de la insipiencia con que han procedido los intérpretes del modernismo es otro error inicial de enfoque. Consiste en haber tomado como modernismo lo que sólo fue una fase o aspecto del mismo: aquella variante preciosista o afrancesada que Nájera inició y acaudilló Rubén Darío entre 1888 y 1898."3

Se ha subrayado tal vez demasiado la ausencia de contenido humano en dicho movimiento. Cuando se ha reconocido dicho contenido en alguna obra, se ha lamentado casi siempre el excesivo idealismo o el escapismo ideológico.

Sin embargo hay otros aspectos del movimiento modernista en el Rio de la Plata que merecen atención. La crítica parece haberse limitado a un aspecto del modernismo: la prosa culta, o mejor, "d'élite".

$\mathrm{Si}$ se estudian especialmente los conceptos de modernismo y americanismo en una más amplia acepción, como destaca Emir Rodríguez Monegal en la introducción a las Obras Completas de J.E. 
Rodó ${ }^{4}$, o las tendencias realistas y naturalistas de la novela y el teatro, se puede llegar a una interpretación más crïtica de la poética modernista.

Refiriéndome a la introducción antes citada quiero subrayar el significado y la importancia de la tradición tal cual se destaca en la visión abarcadora del americanismo de Rodó.

En realidad su americanismo descansa en el concepto (más universal) de tradición. Desde 1895, y en sus artículos de la Revista Nacional, manifestaba su conciencia de la tradición no como la sujeción supersticiosa a un conjunto de reglas absolutas, sino como una fuerza que sostiene al hombre en su marcha hacia el futuro.... La tradición vista como continuidad; la tradición complementada por la facultad de asimilar lo nuevo; la tradición como sustento de la originalidad nacional: esos son los elementos que el análisis de Rodó arroja. 5

A la luz de este concepto dinámico de tradición me propongo examinar en este trabajo un aspecto fundamental de la poética modernista tomando como base géneros populares o por lo general desatendidos o mal interpretados por la crítica rióplatense.

Empezaremos con un texto de Borges. Este termina su artǐculo sobre "Eduardo Gutiérrez, escritor realista"6 con estas palabras:

Eduardo Gutiérrez, autor de folletines lacrimosos y ensangrentados, dedicó buena parte de sus años a novelar el gaucho según las exigencias románticas de los compadritos porteños... Su prosa es de una incomparable trivialidad. La salva un solo hecho que la inmortalidad suele preferir: se parece a la vida.

Al leer las obras de E. Gutiérrez y en particular Juan Moreira se comprenden perfectamente estas afirmaciones de Borges, convalidades en los años anteriores por el enorme éxito que tuvo la transposición teatral de esta misma obra. Borges llama "trivial" a la prosa de E. Gutiérrez, y García Velloso, en Memorias de un hombre de teatro, nota "la gracia un poco desgarbada del estilo."7 Estas críticas son acertadas pero poco importa este descuido en la forma de Juan Moreira que comenzó a publicarse en folletin en La Patria Argentina el 28 de noviembre de 1879 y terminó el 8 de enero de 1880 . Todo el mundo ya conoce la anécdota de que el autor "en su modesta casita de Flores escribia con lápiz sus folletines, que traía todas las 
mañanas al centro, concluyéndolos muchas veces en el tranvía de caballos... y su horror ante las galeras de imprenta era tal, que nunca corrigió las pruebas de lo que escribia."8 Lo que interesa es el éxito del personaje en sî mismo que conquistó a la gente común a través de un medio tan popular como el folletín.

A pesar de la difusión enorme que alcanzó Juan Moreira, la crítica casi siempre ha ignorado a $\mathrm{E}$. Gutiérrez o le ha dedicado pocas líneas en el capítulo del Teatro Nacional sin tomarlo nunca en consideración como novelista, y la sola calificación que se le ha aplicado es la de folletinista. Como nota García Velloso en sus Memorias: "A E. Gutiérrez le perjudicaron desde el punto de vista artístico ante los lectores de "élite", la forma en que dilapidó su talento abordando temas de actualidades policiales, los títulos casi siempre de mal gusto a fuerza de ceñirlos llamativamente a las exigencias folletinescas, el método frenético de su producción", y más adelante agrega "Día vendrá en que se haga una revisión minuciosa y pulcra de ocho o diez obras de Eduardo Gutiérrez, y entonces se habrán incorporado a perpetuidad, al acervo de la literatura argentina unas de sus expresiones más nobles, más interesantes y más bellas, que por desidia de la crítica, por desprecio de los lectores de "élite", fueron excluídas o tenidas como cosa subalterna. La contradicción entre la popularidad de estas producciones y la falta de consideración y de respeto que tuvieron la crítica y los comentaristas literarios contemporáneos de E. Gutiérrez, se echa de ver al pasar revista a las antologías y a las colecciones de Trozos Escogidos confeccionados en el país. Ni como curiosidad bibliográfica se transcribe en esos libros, llenos de cosas vulgares, aburridas, estúpidas a veces, una página de E. Gutiérrez."9 Juan Moreira tiene tanto éxito porque se inspira en un personaje real y coincide con una saturación del tema gauchesco en el ambiente ciudadano. Recoje la tradición literaria patentizada en los "diálogos patrióticos" de Bartolomé Hidalgo, en la poesía romántica de La Cautiva de Esteban Echeverria, en las composiciones legendarias de Hilario Ascasubi, Bartolomé Mitre, y sobre todo en el poema Martin Fierro de José Hernández, publicado en el año 1872, siete años antes de aparecer el folletǐn de Gutiérrez.

El público criollo está impregnado de simpatỉa hacia el gaucho, hay en el medio popular una disposición hacia este tipo humano.

Gutiérrez ahondaba con su obra en el sentir popular, en el alma del pueblo, educado en el latente odio hacia las autoridades y la defensa del más débil, confirmada en esa época por las frecuentes prepotencias en el interior del país de los caudillos y autoridades políticas locales que cometían atropellos e injusticias de pura arbi- 
trariedad. A este propósito es interesante el trabajo sobre Juan Moreira del periodista Julio Piquet publicado en Tribuna de Buenos Aires el 15 de mayo de 1891 y que cita Vicente Rossi en su Teatro Nacional Rioplatense:

Juan Moreira tiene éxito porque sus perfiles son reales, porque reproduce fielmente escenas de nuestra vida campestre, tan original y pintoresca, porque exalta las pasiones generosas, porque endiosa el valor, porque la ira es santa cuando es justa y Juan Moreira en lucha con la justicia que la azota, le asesina al padre inerme y pretende mancillarle la esposa, es una hermosa encarnación de la ira ciega pero tan noble como el heroísmo. 10

Estas impetuosas palabras de Julio Piquet se justifican del todo si releemos la introducción que el mismo Gutiérrez pone a su novela. Allí está perfectamente explicada toda la trayectoria moral de su personaje, "el motivo poderoso . . . . que empujó por la pendiente del crimen a un hombre nacido con todas las condiciones de un bello espiritu, y que hasta la edad de treinta años fue un ejemplo de moral y de virtudes." 11

Las detalladas descripciones que Gutiérrez hace del cepo, instrumento de tortura de la época, de las jornadas electorales de entonces, sus alusiones al sueldo que recibian los indios de la frontera, son todos elementos muy realistas que hacen que su novela-como dice Borges-se parezca a la vida.

Considerando entonces la novela Juan Moreira, hemos visto como esta obra da nueva vida al folletín de éxito popular por incorporar a su narración elementos de mayor fuerza naturalista que Gutiérrez toma de la crónica policial. Se puede encontrar aquí una primera etapa de lo que se podrỉa llamar el reciclaje de un género popular, despreciado por el lector culto.

Cuatro años después de la primera publicación de la novela, Juan Moreira adquiere nueva vida en el teatro o mejor dicho en el circo.

El circo criollo en su doble expresión de espectáculo acrobático y teatral constituía en esa época la diversión preferida de las clases populares y era caracterǐstico que se insertara como final en el programa circense una pantomima. Fue en 1884 que los hermanos Carlo que actuaban en el Politeama Argentino con su circo, buscando una novedad para renovar su programa-bajo sugerencia del mismo Gutiérrez-contrataron a José Podestá, que en ese entonces represen- 
taba en el Circo Humberto I el famoso payaso "Pepino 88", para interpretar en pantomima el conocido personaje folletinesco Juan Moreira.

Las mismas palabras de Pepe Podestá transmitidas por García Velloso en sus Memorias atestiguan el suceso que encontró en la escena este gaucho cuyas aventuras ya todo el mundo conocía. Relata Podestá:

Alcanzamos un éxito colosal, que yo lo presentía con una fe tan segura, que no me falló un punto, ni en el momento tremendo de salir al picadero, para que Don Francisco me pusiera de cabeza en el cepo.... Yo tenía una gran esperanza en las peleas con la "partida" y en los cuadros netamente criollos, en los que intervenían unos negros que habíamos contratado para que jineteasen e hicieran "rayar" los pingos en la entrada de la fiesta campera. ${ }^{12}$

Tres elementos contribuyen fundamentalmente a este éxito: el personaje de Juan Moreira en que el pueblo se vió proyectado, el circo que entonces era el máximo entretenimiento popular y José Podestá que actuando con los cantos y los modales del orillero criollo, incorporó a la dramatización elementos veristas que tanto arraigo tenían en el público. Como observa Vicente Rossi "Aquel auditorio, criollo en su inmensa mayoría, no estaba acostumbrado a tanto verismo en la escena, y mucho menos a que ese verismo tocase tan en carne viva su idiosincrasia." 13

Dos años más tarde del estreno del mimodrama de la obra de Eduardo Gutiérrez, la compañia Podestá-Scotti se encontraba con su circo en Arrecife. Bajo consejo de M. Léon Beaupuy "un francés muy simpático y muy inteligente" dueño del hotel donde se alojaba la compañía, Pepe Podestá que captó de inmediato la importancia de la idea, agregó diálogos correspondientes a la acción mímica de Juan Moreira. $\mathrm{Y}$ así, transformada la pantomima en drama hablado se estrena por primera vez el diez de abril de 1886 en la localidad de Chivilcoy con una aceptación completa por parte del público.

La pantomima inicial queda así superada. Con el tiempo y el éxito siempre mayor se le fueron añadiendo nuevos cuadros, nueva música-la del pericón de la ópera criolla Por Maria-y también nuevos personajes como el mercachifle napolitano Antonio Cocoliche, creado por Celestino Petray.

Como se ve, Juan Moreira, evolucionaba dentro de sus mismas tradiciones al incorporarse en la obra nuevos agregados sacados de las costumbres y vida real de la época. 
De nuevo cito a García Velloso:

Todo lo que se fue agregando luego sirvió para alargar el espectáculo, sin aportarle a la admirable tragedia ningún elemento superior de emoción o de interés ... Era la perfección teatral absoluta en la evocación de los tipos, en el abandono candoroso en el decir y en el hacer; la vida misma transportada al picadero y al tabladillo. ${ }^{14}$

Y aquí otra vez García Velloso coincide con Borges.

Al ser trasladado el Juan Moreira, del folletìn a la pantomima, por obra de los hermanos Podestá en el circo Politeama y más tarde por la transformación de la pantomima en sketch dramático, se produce no sólo una ampliación del area de difusión de la obra, sino un refuerzo de sus aspectos más populares. Al mismo tiempo las exigencias de la representación teatral tienden a acentuar el carácter realista y hasta naturalista del texto original. En esta segunda etapa no hay propiamente un reciclaje todavia, ya que se trata de la transposición de un género popular a otro.

La tercera etapa de la transformación que estamos comentando va a completar y perfeccionar el reciclaje. Esta ocurre cuando los elementos populares del dramita de circo contribuyen al éxito de este tipo de teatro y permiten la fundación de un teatro burgués en el Rio de la Plata. Me refiero a las obras de Florencio Sánchez y de Ernesto Herrera (para citar los ejemplos más conocidos) que alcanzarán éxito en el público de las dos capitales platenses: Montevideo y Buenos Aires.

Florencio Sánchez y Ernesto Herrera no hacen brotar el teatro nacional de la nada. Ambos estaban impregnados de las ideas anarquistas de Malatesta que por ese tiempo se hallaban en plena expansión en el Río de la Plata. En cierto sentido es la corriente realista penetrada de un impreciso estado sentimental-anárquico que los empuja a insertar en sus obras elementos de espontaneismo rebelde tomados de la tradición teatral moreirista.

Asi que el gaucho vuelve y penetra en el teatro, pero es un gaucho nuevo "el de bombacha, siempre altivo, generoso y patriota, aunque no use el chiripá, sus sentimientos son los mismos de sus antecesores, aunque el ambiente en que actúa es otro."15

Con Juan Moreira a fines del siglo XIX hemos visto representado a un personaje rural en un ambiente aldeano. Si literariamente esta obra corresponde al Naturalismo, desde un punto de vista 
sociológico representa la absorción de la comunidad campesina por la ciudad. En esta migración interna el gaucho matrero se hace compadrito.

En La Gringa y Barranca Abajo de Florencio Sánchez advertimos en los dos personajes clave de las obras la evolución que ha tenido el gaucho después de Juan Moreira.

Como nota Roberto Giusti16 Sánchez no fue un creador de caracteres y sus personajes no tienen una marcada profundidad psicológica; están vistos desde afuera como tipos relacionados con determinados ambientes y situaciones coloridas de la vida campesina que Sánchez pinta con ojos casi fotográficos.

Don Cantalicio, el viejo criollo de La Gringa se caracteriza por su impulsividad que fue también rasgo dominante en la personalidad de Juan Moreira. La impulsividad en Don Cantalicio es a veces patética porque se manifiesta en situaciones que denotan su ingenua ignorancia, o mejor dicho, rechazo hacia el progreso y la civilización.

Aquî son los gringos-"estos ladrones" según Cantalicio-que representan al progreso y a la civilización; ellos con nuevas técnicas y máquinas han mejorado y hecho prosperar el campo que en las manos de Cantalicio-a pesar de sus esfuerzos-no rendía nada.

Próspero, el hijo, con su distinta visión de la realidad aisla mayormente la figura paterna y en sus palabras: "Amalaya nos fuéramos juntando todos los hijos de criollo y de gringo, verían qué cría ¡"17 plantea y sintetiza el tema de toda la obra: la fusión del extranjero con el criollo. Y si al final Cantalicio acepta la unión entre su hijo y Victoria, sin embargo para él los viejos gringos serán siempre "los ladrones" que le han hecho "todas las judiadas" entre las cuales el querer voltear al ombú "que no es de ellos. Es del campo. Canejo i"18 Quiero detenerme en este episodio, uno de los más sentidos de la obra, porque en las palabras de rencor de Cantalicio está condensado todo el animismo típico de los viejos criollos arraigados a su tierra, y cito: "Los ombuses son como los arroyos o como los cerros. Nunca he visto que se tape un ròo pa ponerle una casa encima, ni que se voltee una montaña pa hacer un potrero. Asesinos! ; No tienen alma! Si tuvieran algo adentro les dolerìa destruir un árbol tan lindo, tan bueno, tan mansito...."19 Esta desesperación de Cantalicio aparece aún más dramática si le damos un significado simbólico identificando al mismo personaje con el ombú. El volteamiento de este último toma para el viejo criollo el significado de una completa derrota que explica su deseo de acabar su vida con la del ombú. En esta obra de F. Sánchez como en Barranca Abajo los 
personajes están situados en ambientes rurales pero ya la inmigración extranjera y la explotación moderna de las estancias han hecho obsoleta la figura del gaucho.

En La Gringa se dan dos posibilidades:

A) Cantalicio, el gaucho que resiste y es desplazado (mutilado simbólicamente);

B) Próspero, el gaucho que se adapta y se convierte en paisano. Literariamente el Naturalismo aparece suavizado por un simbolismo optimista.

En Barranca Abajo la dramaticidad de Don Zoilo tiene raíces más hondas que la de Cantalicio y entre los caracteres de F. Sánchez, aquél es sin duda, el más firmemente trazado. A diferencia del viejo criollo de La Gringa, que desde el principio está presentado como un personaje vencido, el dolor de Don Zoilo, reprimido en las primeras páginas, estalla del todo en el último acto que se concluye con su gesto dramático.

Sus palabras, al final de la pieza, resumen la trayectoria de su desdicha, muy similar en cierto sentido, a la de Juan Moreira:

Agarran a un hombre sano, güeno, honrao, trabajador, servicial, lo despojan de todo lo que tiene, de sus bienes amontonados a juerza de sudor, del cariño de su familia, que es su mejor consuelo, de su honra ... canejo! que es su reliquia; lo agarran, le retiran la consideración, le pierden el respeto, lo manosean, lo pisotean, lo soban, le quitan hasta el apellido...y cuando ese disgraciao, cuando ese viejo Zoilo, cansao, deshecho, inútil pa todo, sin una esperanza, loco de vergüenza y de sufrimientos, resuelve acabar de una vez con tanta inmundicia de vida, todos corren a atajarlo. No se mate que la vida es güena! ... Güena ... pa qué? .20

Su personalidad tiene una dignidad, aun cuando decide matarse, que falta en Cantalicio, porque el dolor de Zoilo es el dolor del hombre no sólo acosado por la injusticia sino por la maldad de la misma familia que le rodea. Cuando su hija Robustiana, el único afecto que le quedaba y justificaba su vida, se muere, Zoilo no tiene más razón para seguir adelante y entonces su gesto es la justa conclusión de su dolor.

En Barranca Abajo el suicidio de Zoilo representa la sola posibilidad de salida para el gaucho. Aquǐ el Naturalismo aparece en su forma más trágica y negativa. 
A los dos personajes considerados hay que agregar un tercero Don Gumersindo, viejo caudillo ciego de El León Ciego, la obra más importante de Ernesto Herrera, y se verá complementada la parábola que venǐa desarrollándose desde Juan Moreira.

El viejo caudillo Don Gumersindo tiene una dimensión distinta a la de Cantalicio o Zoilo. Se parece a ellos por el fuerte individualismo psicológico, el sentimiento de honor y de la tradición-comunes también a Juan Moreira-pero se acerca más a este último en el coraje unido al desprecio total por la vida, si ésta no tiene por objeto la libertad absoluta. "Este hombre es el integrante de la independencia política nacional, de las fuerzas originales de la anarquía argentina y las guerras civiles orientales" comenta Walter Rela.21 La impulsividad y el fuerte individualismo de un Juan Moreira aquí están encauzados en un Don Gumersindo movido por una auténtica pasión guerrillera en la lucha contra el coloniaje.

Su derrota no se debe a la injusticia, o a la ley, sino a los tiempos que han cambiado y él mismo lo afirma: "Los hombres, canejo! Los hombres es que no son los que eran antes" 22 y el joven Arturo como Próspero en La Gringa le contesta: "Sỉ pero... hay que adaptarse a la época".

Es este desajuste con la realidad en que viven que constituye el enemigo principal de estos viejos criollos como Gumersindo, Zoilo o Cantalicio; desajuste, que ellos no logran superar y que fatalmente los mata o los deja completamente derrotados, o sea psicológicamente muertos.

Si en las obras de Sánchez el ambiente puede ser rural argentino o uruguayo, El León Ciego refleja otra situación que se dio sólo en el Uruguay al principio del siglo XX: el gaucho que sobrevive como caudillo en las guerras civiles. Desde el comienzo de la obra, Gumersindo está presentado en decadencia y es en esta visión negativa del personaje que se manifiesta el Naturalismo de El León Ciego.

Estas tres obras, más otras que no he mencionado, fundan una nueva literatura dramática en que la semilla del Naturalismo-ya contenida en la novela folletinesca de Eduardo Gutiérrez y en la adaptación escénica de los Podestá-fructifica completamente, enriqueciendo el modernismo ríoplatense con un vigoroso conjunto de obras.

Universiti di Milano, Yale University 


\section{NOTAS}

1. Para la prosa modernista consúltese especialmente: Amado Alonso, Ensayo sobre La Novela Histórica-El modernismo en La Gloria de Don Ramiro, (Buenos Aires: Instituto de Filologia, 1942); Alfredo A. Roggiano, "El modernismo y la novela en la América Hispana", La novela hispanoamericana, org. J. Loveluck. Memoria del V Congreso del Instituto Internacional de Literatura Iberoamericana, (Albuquerque, New México, 1951); Max Henríquez Ureña, Breve historia del modernismo, (México: Fondo de Cultura Económica, 1954); Roberto Yahni, Prosa modemista hispanoamericana, Antología, (Madrid: Alianza Editorial, 1974); Olivio Jiménez-R. de la Campa, Antología crítica de la prosa modemista hispanoamericana, (New York: Eliseo Torres \& Sons, 1976); I. Chiampi Cortez, "Para una semiologia de la prosa modernista", ponencia presentada en el XVII Congreso Internacional de Literatura Iberoamericana, (Gainesville, Florida, abril 1977).

2. M. Pedro González, "En torno a la iniciación del modernismo", en Homero Castillo, Estudios críticos sobre el modernismo, (Madrid: Gredos, 1968), p. 212.

3. Op. cit., p. 213.

4. E. Rodrïguez Monegal, "Introducción" a Obras Completas de José Enrique Rodó, (Madrid: Aguilar, 1967).

5. Op. cit., p. 104.

6. Borges, en El Hogar, (Buenos Aires, 9 de abril de 1937).

7. Garcia Velloso, Memorias de un hombre de teatro, (Buenos Aires: Kraft, 1942), p. 175.

8. Op. cit., p. 177.

9. Op. cit., p. 176.

10. Vicente Rossi, Teatro Nacional Ríoplatense, (Buenos Aires: Solar/ Hachette, 1969), p. 95.

11. Eduardo Gutiérrez, Juan Moreira, (Buenos Aires: Eudeba, 1961), p. 19. Que el verdadero Moreira del partido de Navarro haya sido en la realidad, como lo destaca el Dr. José Ingenieros, citado por Garcìa Velloso, "un facineroso de la peor especie vago, mal entretenido, de pésima ìndole moral y de escaso intelecto", a nosotros no nos interesa. Nuestro Juan Moreira es el arquetipo de E. Gutiérrez, el héroe anárquico e idealista que creó la leyenda en el alma popular.

12. Garcïa Velloso, op. cit., p. 157.

13. Vicente Rossi, op. cit., p. 39.

14. Garcia Velloso, op. cit., p. 166.

15. Vicente Rossi, op. cit., p. 64.

16. Roberto Giusti, Florencio Sánchez: su vida y su obra, (Buenos Aires: Editorial Justicia, 1920)

17. Florencio Sánchez, La Gringa, (Buenos Aires: Colección Estrada, 1946), p. 13. 
18. Op. cit., p. 45.

19. Ibid., p. 45.

20. Florencio Sánchez, Barranca Abajo, Buenos Aires: Colección Estrada, 1946), p. 180.

21. Walter Rela, "Prólogo" a Ernesto Herrera, Teatro Completo, (Montevideo: Colección de Clásicos Uruguayos, 1965).

22. Op. cit., p. 105. 
